\title{
Resistance to extinction as a function of nonresponse incentive shift'
}

\author{
D. GENE DAVENPORT AND JOHN H. MUELLER \\ SAINT LOUIS UNIVERSITY
}

Rats were given 50 direct placements in the goalbox following 50 acquisition trials in the complete runway. Extinction performance was found related to reward levels in both placement and acquisition, with the larger reward less resistant.

The procedure used in incentive shift studies (cf. Pubols, 1960) has normally required the animals to continue responding to the new reward value, so that, except for the first postshift trial, further learning is confounded with incentive motivation effects. Trapold \& Bell (1964) have investigated incentive changes through the use of direct placement (DP), thus introducing a new level of reward in the absence of the complete runway response. When compared to a group shifted to a larger reward after DP, the group shifted up during DP exhibited a lasting performance gain, a "priming" due to DP reward increase.

The purpose of the present study was to investigate the effects on resistance to extinction (RE) of incentive shifts introduced during DP trials. By increasing the incentive values in given cases, and by reducing these values to zero as well as nonzero levels, the methodologies of incentive shift and latent extinction are combined in order to clarify the characteristics common to both areas.

\section{Subjects}

The Ss were 36 male Sprague-Dawley albino rats, approximately 100 days old. Eighteen Ss were used in each of two replications.

\section{Apparatus}

The apparatus consisted of a 33 in. Hunter Model 380 straight runway. End boxes were $12 \mathrm{in.} \mathrm{long}$ direct extensions of the alley, so that a distance of 45 in. separated the startbox and the food cup. The goalbox was differentiated from other parts of the runway by strips of black tape placed at 1 in. intervals vertically along the walls and across the roof. Time was measured to the nearest $0.01 \mathrm{sec}$ in two segments of the runway: the first 4 in. past the startbox door (start time), and the remaining 41 in. (alley time). Procedure

The experiment was conducted in two procedurally identical replications. Animals were of the same age in each replication, with greater homogeneity of weight in the second replication the only apparent difference. Prior to the beginning of runway training, Ss were reduced to $80 \%$ of their base weight and given two sessions of approximately ten min duration in the apparatus for magazine training. The Ss were run in groups of three, with each $S$ given a trial before any animal received his next trial, so that an intertrial interval of about $2 \mathrm{~min}$ resulted. The Ss not leaving the startbox within $60 \mathrm{sec}$ were pushed into the alley, and those not entering the goalbox within $60 \mathrm{sec}$ after leaving the startbox were pushed into the goalbox. A $30 \mathrm{sec}$ goal confinement period was used in each stage, and all trials and DPs were distributed five per day.

In each replication, a 2 by 3 factorial was used. During training, nine Ss received a one pellet reward $(0.045 \mathrm{~g})$ for each of 50 running trials, while the other nine were given ten pellets. Following acquisition, each of the two training groups was divided into three groups and given 50 DP trials with either zero, one, or ten pellets reward. The groups may be symbolized as follows: $1-0,10-0,1-10,10-1,1-1,10-10$, where the numbers are training and DP reward magnitudes respectively. For the DP trials, each $S$ was placed directly into the goalbox by $\mathrm{E}$, so that the $\mathrm{S}$ was oriented toward the food cup, but was about 4 in. from the cup. After the DP trials, Ss were given 30 running extinction trials.

\section{Results and Discussion}

Start time and alley time, as previously defined, were converted to speed scores by a reciprocal transformation. Alley speed (AS) was found to be the more stable measure and will be the response unit reported here. The effects of two replications, two training rewards, and three DP rewards on the 30 extinction trials was evaluated by a 2 by 2 by 3 analysis of variance (ANOVA) with 30 repeated measures. Both the training $(F=6.98, \mathrm{df}=1 / 24)$ and the $\mathrm{DP}(\mathrm{F}=\mathbf{7 . 5 9}$, df $=2 / 24$ ) reward levels produced significant main effects, with no interaction ( $F=1.09, \mathrm{df}=2 / 24)$. Figure 1 indicates that ten pellets reward, whether during training or DP, resulted in less RE than one pellet, and that zero DP reward resulted in the least $R E$. Individual comparisons of the DP reward levels indicated that only the extremes, zero and one, were significantly different. The only significant interaction was the trials by replications $(\mathrm{F}=2.48, \mathrm{df}=29 / 696)$, reflecting the somewhat lower performance level in the first replication. The fact that other interactions with replications were nonsignificant, as well as the main effect of replications $(\mathrm{F}<1.00, \mathrm{df}=1 / 24$ ), provided the basis for combination of replications in Fig. 1.

Since the groups started testing at different levels because of training effects $(F=4.05, d f=1 / 30)$ and the nonsignificant DP subgroup differences $(F=1.04, \mathrm{df}=$ 2/30) apparent in Fig. 1, a "difference" analysis was computed to clarify the interpretation of the early 


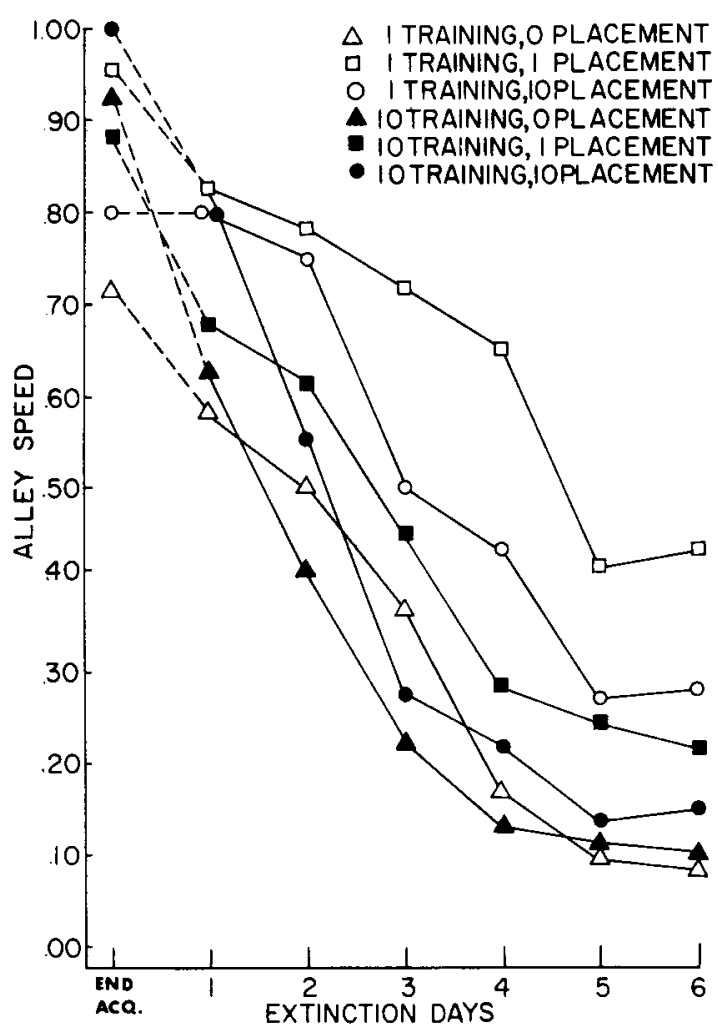

Fig. 1. Alley Speed during Extinction. Means for Blocks of Five Trials, Combined Replications.

extinction trials. The data for this 2 by 3 by 3 ANOVA were the differences for each $\mathrm{S}$ between AS on extinction trial $\mathrm{N}(\mathrm{N}=1-5)$ and the mean $\mathrm{AS}$ on the final training day. Even with this correction, a significant training effect resulted $(F=13.61, \mathrm{df}=$ $1 / 24$ ) with a significant DP by trials interaction ( $F=$ 2.20, $\mathrm{df}=8 / 96$ ), but the DP main effect was absent ( $F<1.00, d f=2 / 24)$. Neither main effect was significant when this analysis was restricted to the first trial alone $(F s<1.00)$. It is apparent that the DP reward level effects developed gradually, somewhat contrary to the expectation (Dyal, 1962) that increasing the number of DPs increases the effects of DP.

A comparison in Fig. 1 of the 10-1 group with its regular control group (1-1) suggests the development of shift effects over the extinction trials, although the effects are not present on the early trials as might be expected from incentive motivation theory. Similarly, a comparison of the 1-0 and 10-0 groups suggests a greater reduction with the larger shift. It seems, however, that these findings are well accounted for in terms of the number of large and small rewards given, without reference to shift effects per se. Sperling (1965) has noted that increasing the training with large rewards produces greater $\mathrm{RE}$, whereas with small rewards it decreases RE. In the present study, Ss given 100 trials with small reward (1-1) were the most $R E$, and those given 100 trials with large reward (10-10) were the least $\mathrm{RE}$, with the mixed groups in between. If this interpretation is legitimate, it would seem that the alternative interpretation in terms of runway length (Clifford, 1964) is less crucial, since the "long" runway acquisition trials and the "short" runway DP trials produced comparable effects in this study. It is suggested that the general area of reversal shift in discrimination learning and the related area of $R E$ in general may be of more relevance to the incentive shift studies than is immediately obvious. Just as reversal shifts are not immediate, with a variety of factors which influence the speed of shifting, similar factors may influence the course of behavior brought about by incentive shift in the runway.

\section{References}

CLIFFORD, T. Extinction following continuous reward and latent extinction. $J$. exp. Psychol., 1964, 68, 456-466.

DYAL, J. A. Latent extinction as a function of the number and duration of pre-extinction exposures. J. exp. Psychol., 1962, 63, 98-104.

PUBOLS, B. H. Incentive magnitude, learning, and performance in animals. Psychol. Bull, 1960, 57, 89-115.

SPERLING, SALLY, E. Reversal learning and resistance to extinction: a review of the rat literature. Psychol. Bull., 1965, 63, 281-297.

TRAPOLD, M. A., \& BELL, J. E. Effect of noncontingent exposure to shifts in reward magnitude on subsequent instrumental runway performance. Psychol. Rep., 1964, 15, 679-684.

\section{Note}

1. Based on a thesis presented to the Graduate School of Saint Louis University by the second author in partial fulfillment of the requirements for the M. S. degree. This research was supported in part by NASA Training Grant NsG (T) - 74, Supplement No. 3, awarded to the second author. 